Letras, Lima. 1977-79. (Nos. 86-87), 161-164.

\title{
La novela latinoamericana y la cultura italiana
}

\author{
MARIA ROSARIA ALFANI
}

El interés que la literatura hispanoamericana ha despertado en Italia en los últimos diez años, tiene un antecedente muy cercano en el tiempo: el descubrimiento de la literatura norteamericana.

A finales de los años 40, para el editor Einaudi, trabajan como traductores Cesare Pavese y Fernanda Pivano, los nombres de punta de la cultura italiana de aquellos años, la más vital, ligada al capital y a la industria cultural que recién nacía.

El trabajo de estas vanguardias culturales, hace de manera que Steinbeck, Faulkner y después Hemingway, se difundan en el público medio.

En los años 50, Fernanda Pivano, traduce Spoon River Anthology, que tiene enorme difusión, aunque generalmente en Italia la narrativa se prefiere a la poesía.

Llega a Italia, también Ha nuevál cultura norteamericana: además de Henry Miller, Kerouac y sus beatniks, Salinger con sus adolescentes problemáticos y el budismo zen, es decir el "disenso" que en estos años empieza a formarse y confirmarse en la West Coast.

A la influencia de la literatura norteamericana, hay que adscribir Uomini e no di Elio Vittorini, con su técnica behaviorista, cinematográfica y los tres tomos de Americana, siempre de él.

Si los años 50, son los años de la literatura, del cine y de la música de Norteamérica, los años 60 son los de las artes visuales.

La Bienal del 62 y la del 64 , hacen conocer a Rauschenberg y el pop art; ya no se puede hablar de "boom", sino de presencia, de término de relación y verificación constante y obligada.

Esto tiene explicaciones políticas y sociológicas.

El fascismo impuso a Italia un gran aislamiento cultural: la autarquía económica, significó autarquía cultural.

Y la invasión armada de los norteamericanos, comportó el deseo, la curiosidad de identificar culturalmente a este invasor escondido en un uniforme. 
Además Estados Unidos imponen a Europa y a Italia de particular manera, extremada por la guerra, su hegemonía política y económica, que se le impone como modelo cultural. Italia acoge sin discriminación los productos de élites (la literatura) y los deteriores: el hula-hop, por ejemplo; en suma la cultura de vanguardia y la de masa.

El "boom" de la narrativa hispanoamericana comienza en el 67 con la publicación de Cien años de Soledad, de Gabriel García Márquez: un éxito editorial sin precedentes.

Es cierto que Borges y Cortázar y Lezema Lima, en la novela, y Neruda en la poesía eran nombres ya conocidos en Italia, pero por un público limitado, casi especializado, y hay que agregar que Borges y Cortázar, por ejemplo, no son voces argentinas, sino por razones referenciales y circunstanciales: ellos son en realidad exponentes de una cultura refinada y cosmopolita y portadores de una problemática intelectual y estética local, sólo en sus referentes inmediatos.

De formación europea, ellos pertenecen al país más industrializado del Sur de América, a la realidad urbana y europeizante de Buenos Aires.

En cambio Cien Años de Soledad, es un libro local y ligado a problemas concretos, sociales, culturales y políticos de Colombia en cierta fase de su desarrollo socio-económico.

Es la metáfora de la historia del entero continente, contada por un hombre al que la cultura no ha diluido y extenuado, sino exaltado y fortificado los vínculos con su tierra y sus mitos.

El éxito editorial de Cien Años de Soledad debido al gusto con que se ha leído no sólo por masas de lectores, sino también por los especializados, ha desencảdenadocinemultiplicádo $\mathrm{Oas}$ iniciativas editoriales: Einaudi y Feltrinelli, han difundido en Italia los libros de Vargas Llosa, Argüedas y hasta escritores de interés local, como Julio Ramón Ribeyro y después Alfredo Bryce Echenique.

Se vuelven a editar las novelas de Carpentier, los cuentos de Cortázar, Donoso, Roa Bastos, en suma toda la narrativa latinoamericana de los años 60 .

El aparecer de esta narrativa, corresponde a un momento histórico de transformación en Latinoamérica y al formarse de una nueva conciencia política: a fines de los 60 el Che, ya leyenda, realiza su experimento de guerrilla, en Chile arranca el proceso político que va a llevar a Allende al poder, sin dejar a Velasco, que en su intento revolucionario, privilegia precisamente al componente indígena de la población y apunta en la valorización de la cultura nacional.

Todo esto tiene vida breve: la década de los 70 ve el instaurarse de una general tendencia autoritaria, claramente involutiva, en Chile, en Perú, aunque menos abiertamente, y en Argentina. La represión acaba con estos rapidísimos procesos revolucionarios. 
Y también la narrativa sudamericana de estos años, la de Bryce Echenique, la de Manuel Scorza, la del último Vargas Llosa es una narrativa que se rehace a sí misma.

Ya no es reflexión problemática sobre su realidad cultural y política, sino producto de evasión, aunque de buen nivel. Es una narrativa que busca a su público, que está lejos de la literatura, de éste secunda los gustos y se deja acondicionar.

Scorza?.

¿Cómo se explica el éxito que ha obtenido en Italia, hasta Manuel

¿Cuál falta en la cultura italiana, oportunamente individuada por las editoriales, está detrás de estos "exploits"?

Como en los años 40 , después del silencio del fascismo, se pidió linfa nueva a la literatura norteamericana, como compensación del proceso involutivo de la imaginación, que siempre se produce en los momentos de represión de la libertad, en los años 60 el estímulo nuevo viene de Latinoamérica.

La iniciativa editorial que lo sustenta y al final manipula y acondiciona este episodio cultural, tiene menor duración en el tiempo, se agota y se quema más rápido, en perfecta sintonía con los ritmos siempre más veloces de la vida italiana a comienzos de los años 70 .

Los motivos de este fenómeno son culturales y políticos.

Esto acontece en el mismo momento en que los críticos profesionales, y la crítica académica de común acuerdo, empiezan a redactar el acto de muerte de la novela.

Y la narratología, recién nacida, afina sus armas sobre este cuerpo oficialmente declarado muerto.

La reflexión y la teoria substituyen la novela: la narratología se establece en el panotamá cultural con la fuerza y'la riqueza de un nuevo género literario.

¿Había muerto de veras?

Es cierto que Carlo Emilio Gadda, Italo Calvino, los autores más problemáticos culturalmente y más innovadores en el lenguaje y en las técnicas narrativas, nunca han sido bestsellers.

El único boom editorial de estos años, "La Storia" de Elsa Morante, es indudablemente una involución desde el punto de vista de las técnicas expresivas; en cambio sus precedentes novelas, más substancialmente novedosas, fueron patrimonio de pocos.

Es decir que la divergencia que se ha producido entre la literatura y el público medio, ha sido llenada por el cine: la invención, al dejar la palabra, se ha unido a la imagen. O hay que buscarla en episodios, como la narrativa hispanoamericana que manifiesta nuevos espacios.

Muy iluminante es la experiencia artística de Pasolini, que empieza con la literatura, pero a comienzos de los 70 llega definitivamente al cine en busca de mayor comunicación, y sus películas evolucio- 
nan emblemáticamente desde la historia de "Il Decameron" hasta el mito, la infancia mítica del mundo de "Le mille en una notte".

Finalmente esta literatura ha tenido un valor totémico, porque en ella se han reconocido grupos intelectuales, los que en el 68 querían "la imaginación en el poder".

Se ha reconocido en estos libros, huellas del pasado pre-colombino y en éste se ha individuado la realización de la utopía de Marcuse: el triunfo del principio del goce que la cultura occidental dominó y reprimió sobre el principio de la realidad.

El encanto de estas novelas se acrecentó por su proceder de países en que había transformaciones políticas; éstas no sólo han proporcionado el gusto de volver a leer en un momento en que el cuento y la imaginación eran alcanzables para la mayoría sólo en el cine, sino han compensado, en cierto sentido, también las aspiraciones a cambios políticos.

Grupos que aspiran a ser revolucionarios, sin tener el valor de serlo, en víspera del que será sólo un cambio en la continuidad, apagan sus deseos con el vivir los cambios imaginados y frustrados de otros países, de otras culturas, de otras literaturas.

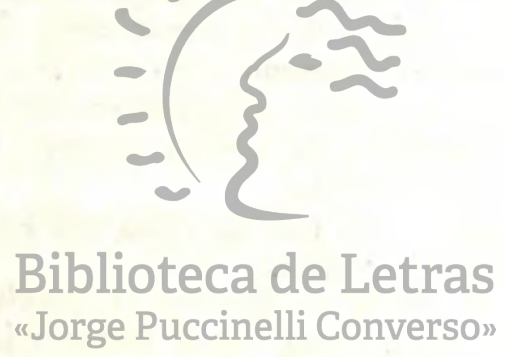

